\title{
"Evaluation of Factors Affecting the Phototherapeutic Properties of Commonly Used Phototherapy Units for Treatment of Neonatal Hyperbillirubinemia in India": A Descriptive Cross Sectional Study
}

\author{
Santosh Kumar $\mathrm{K}^{1 *}$, Mangalabharathi $\mathrm{S}^{\mathbf{2}}$ and Kamalarathnam $\mathbf{C N}^{2}$ \\ ${ }^{1}$ Department of Neonatology, Saveetha medical college and hospital, India \\ ${ }^{2}$ Institute of Child Health \& Hospital for Children, Madras Medical College, India
}

Received: 漹 April 20, 2018; Published: 制 May 03, 2018

*Corresponding author: Santosh Kumar Kamalakannan, Department of Neonatology, Saveetha medical college and hospital, India

\section{Abstract}

Objective: To study the spectral characteristics of the phototherapy systems and to identify variations in spectral properties with changes in height, voltage, tilt and temperature output.

Setting: Research laboratory at a tertiary care hospital.

Methods: The spectral characteristics were measured from two compact fluorescent lamp (CFL) and eight light emitting diode (LED) phototherapy devices in a dark room with an irradiance of $<0.1 \mu \mathrm{W} / \mathrm{cm}^{2} / \mathrm{nm}$. The variations in the spectral characteristics with changes in height, tilt and voltage were measured. Heat output was documented.

Results: The peak spectral wavelength of all the devices tested had a peak centering around $450 \pm 10 \mathrm{~nm}$, in billirubin absorption spectrum. LEDs achieved a higher maximum irradiance compared to CFL units across all the heights tested. CFL and Array LEDs showed a better mean irradiance compared to Spot/Multispot LEDs. CFL and Array LEDs demonstrated the best footprint whereas the Spot and Multispot LED units had a narrow footprint (approximately half or less of CFL or Array LEDs).Tilt angles influenced the mean irradiance. Most of the units showed a decrease in mean irradiance with tilting except for one Array LED namely Brilliance Classic. CFLs showed an inconsistent mean irradiance when tested at different voltage inputs LEDs had a consistent irradiance in spite of voltage fluctuations. LEDs had minimal irradiance decay of irradiance compared to CFLs. Both CFL and LED units showed increasing temperature output over time, which is more pronounced in CFL units.

Conclusion: The phototherapy units differ in spectral properties which influence their therapeutic efficacy. Spectral parameters and its variations with tilt height and voltage changes must be considered when phototherapy device are used. The Array LEDs and CFL devices seem to score over other devices in most of the parameters tested.

Keywords: Neonate; Jaundice; Spectral Properties; Surface Area; Irradiance

\section{Introduction}

Neonatal jaundice is a common problem in day to day practice of a neonatologist. Options for treatment of neonatal jaundice include Phototherapy, Exchange transfusion and drugs. The major factor in phototherapy efficacy is the dose of light delivered, measured in

photons per unit area, making phototherapy conceptually similar to pharmacotherapy [1].

Efficacy of phototherapy is influenced by dose of light which in turn depends on [1] 
a) Spectral qualities of the light source (Peak wavelength and band width)

b) Intensity of the light (Irradiance)

c) Body surface area irradiated ( "footprint "of the light source )

d) Distance between the light and the infant's skin

A thorough evaluation of these spectral qualities of light is essential for optimizing the application of phototherapy in clinical practice.

\section{Methods}

We tested ten brand new phototherapy devices. Tested devices were classified as Spot LED, Multispot / Improvised LED, Array LED and CFL devices based on the source of light used and the arrangement of the light sources within the panel. Spot LEDs were Phoenix LED PT 101 and Billitron 3006.Phoenix PT 101 had four 10 watt LED bulbs arranged in the center of the panel, which creates a beam of spot light. Billitron 3006 consists of 5 LEDs in a single module. Multisport or Improvised LED devices were Billitron 2006 and Billitron 5006. Billitron 2006 consists of 10 LEDs arranged in two modules of 5 LEDs. Billitron 5006 consists of 15 LEDs arranged in three modules of 5 LEDs each.

Array LEDs included were 4 devices namely, Neotech Sapphire 4000, Neotech Seefar 4000 Spot, Brilliance Classic and Brilliance Pro. Array LEDs had LEDs sources arranged across the entire panel. Neotech Sapphire consist of 9 high power blue LEDs. Neotech Seefar Spot 4000 consists of 27 LEDs. Brilliance Classic consists of 12 LEDs and Brilliance Pro consists of 11 LEDs. The CFL devices consists of six $18 \mathrm{~W}$ double folded (8 inches) special blue CFL placed in a rectangular box fitted with a light reflectors. The study was conducted in a dark room with a background irradiance of $<0.1$ $\mu \mathrm{W} / \mathrm{cm}^{2} / \mathrm{nm}$. Tested devices were switched on one hour prior to measurements for warming up. The devices were given a constant voltage of 240 kilovolts during irradiance measurements and the room temperature was maintained between 25 to $30 \stackrel{\circ}{\circ}$.

For the purpose of the measurements a spacer board of packing material was made of dimension $60 \times 30 \mathrm{~cm}$, white card board sheet was placed over this spacer board with $5 \mathrm{~cm} \times 5 \mathrm{~cm}$ grids drawn on it [2]. $2 \mathrm{D}$ silhouette of the hypothetical babies of gestational age 30 and 38 weeks representing $50^{\text {th }}$ centile of the Fenton's 2013 chart were processed from hand draw images. The surface area of the 38 weeks and 30 weeks silhouette was $760 \mathrm{~cm}^{2}$ and $560 \mathrm{~cm}^{2}$ respectively.

\section{Comparison of peak emission spectra}

The peak emission spectrum of the light sources was tested using a portable HR2000CG-UV-NIR optical spectrum analyzer (Ocean Optics Florida, USA). This equipment is a high resolution spectrometer which has a sensor that covers the 200-1100 nm wavelength range and interfaces to a computer via USB port.

\section{Comparison of Maximum spectral irradiance at peak wavelength}

Spectral irradiance $\left(\mu \mathrm{W} / \mathrm{cm}^{2} / \mathrm{nm}\right)$ measurements were made using a handheld power meter Thorlabs PM 100A (Thorlabs In Newton, New Jersey, USA) with sensor S 120C with ability to analyze intensity of light sources between 400 to $1100 \mathrm{~nm}$ with measurement uncertainty of $\pm 3 \%$ between 440 to $980 \mathrm{~nm}$. This machine was chosen as it one of the devices which can be used to measure the light intensity at varying peak emission spectrum.

For measurement purpose the center of the spacer board and the center point of the light sources were placed in a perpendicular straight line, which was confirmed by a laser beam, this alignment was maintained throughout the process of measurements. The measurements were done at the center of the measuring grid and at four peripheral points (at a distance of $15 \mathrm{~cm}$ breadth wise and $30 \mathrm{~cm}$ lengthwise from the center) once a day for three consecutive days and the average of the three readings were taken to give the maximum irradiance at the center and four peripheral points.

\section{Comparison of mean irradiance}

With the spacer board placed under the devices, irradiance was measured at the center point of each of the $5 \times 5 \mathrm{~cm}$ grids at distances of $30 \mathrm{~cm}$ and $15 \mathrm{~cm}$. The mean irradiance was obtained for different heights.

\section{Treatable surface area}

Treatable body surface area was calculated using the indirect method suggested by Vreman et al. [3], 2D silhouettes of hypothetical 38 and 30 weeks baby were superimposed over the irradiance measured using the $60 \times 30 \mathrm{~cm}$ spacer board. Irradiance measurements falling within the silhouettes were used to determine the treatable body surface area.

\section{Decay of spectral irradiance}

Phototherapy systems were allowed to run continuously for duration of one month. Spectral irradiance was checked daily for a period of one month at the center. The decay of spectral irradiance over time was calculated.

\section{Effect of tilt on irradiance}

From the horizontal position a 30 degree and 45 degree tilt was applied to the devices using a goniometer at a constant height of $25 \mathrm{~cm}$ from the measuring grid. The devices were adjusted in such a way that the maximum footprint of light covered the measuring grid .Measurements for irradiance were taken as previously described .The sensor of the light intensity meter was tilted so that the light rays from the tilted phototherapy light sources fell on the sensor.

\section{Effect of Voltage variation on irradiance}

Variation in voltage was brought about by a 3KVA autotransformer. Irradiance at different voltages of 180kilovolts, 
210kilovolts, 240kilovolts and 270kilovolts were measured at the center point of the spacer board at a distance of $35 \mathrm{~cm}$.

\section{Temperature output of the devices}

Temperature output was measured using a FLIR IR camera (Model FLIR-E63900, T 198547, SWEDEN) at distance $25 \mathrm{~cm}$ from the spacer board at the end of one hour, three and five hours after switching on the machines.

\section{Data Entry \& Statistical Analysis}

Data entry was done using Excel 2010 (Microsoft, Redmond, WA, USA). Analysis was done by using Excel 2010 for Windows. Data were presented as mean (SD)

The surface plots for the irradiance were obtained using the Microsoft Excel 2010 version for windows. The color coded 2D plots of the irradiance measurements were done using the same software.
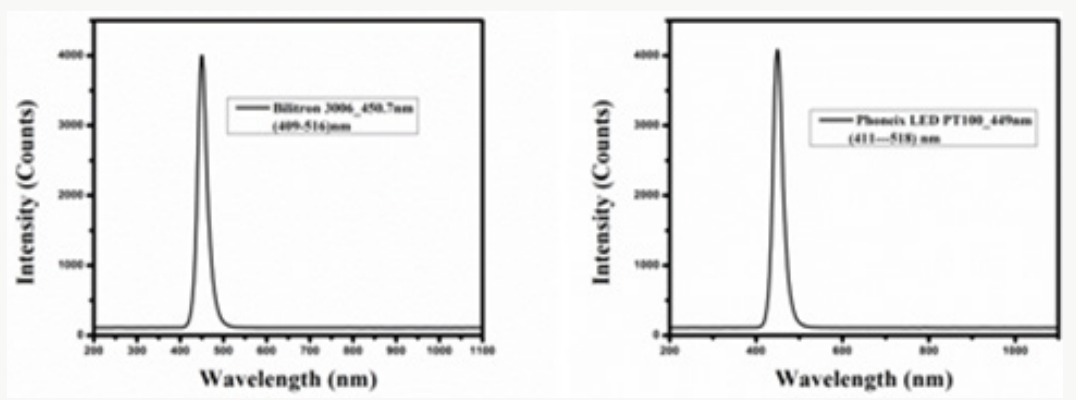

Figure 1a: Spot Led Devices.
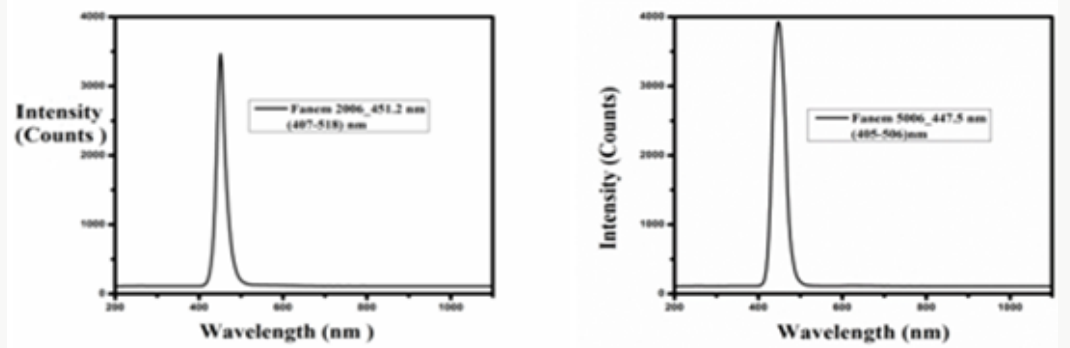

Figure 1b: Multispot/Improvised Led.
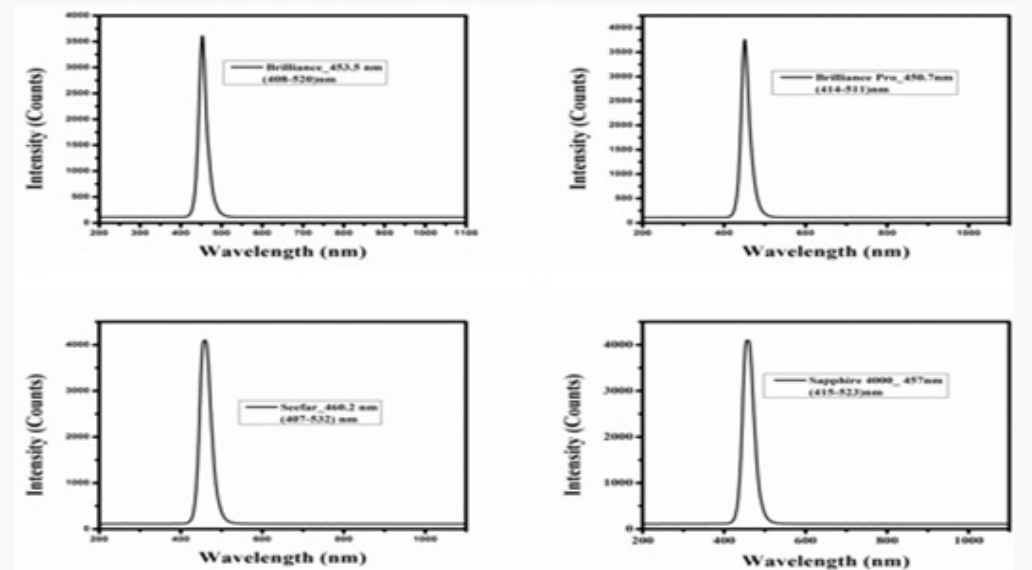

Figure 1c: Array led.
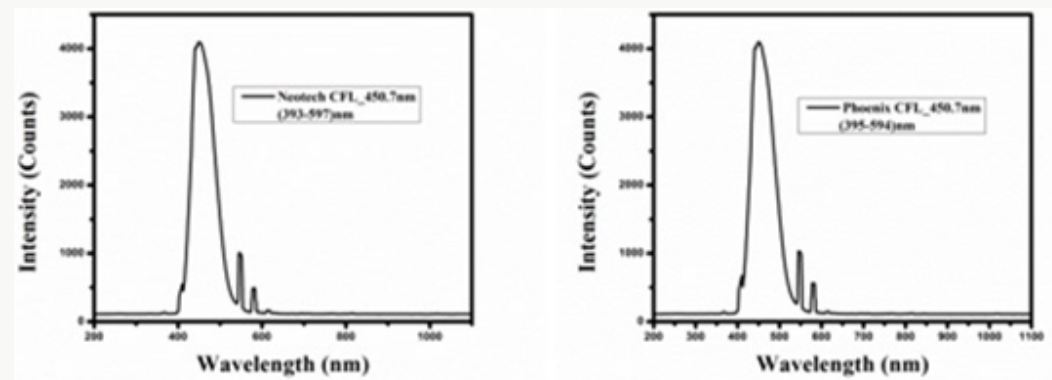

Figure 1d: CFL Devices.

Figure 1: Optical spectral data of the different phototherapy systems. 


\section{Results}

The tested phototherapy devices differed largely in spectral characteristics.The LED devices demonstrated a similar emission spectral range with a narrow band width, while the CFL units had a wider band width. The peak spectral wavelengths of the LED devices tested was around $450 \mathrm{~nm} \pm 10 \mathrm{~nm}$ (Figure 1). The maximum and the mean irradiance within the measuring grid for the phototherapy units at the different heights were tested .Inverse relationship between height from skin and irradiance was demonstrated in all the devices.The spot LEDs had a drastic increase in the maximum irradiance as the height was decreased from $30 \mathrm{~cm}$ to $15 \mathrm{~cm}$ from $67.4 \pm 1.4$ to $215 \pm 1.6$. Among the Mulitspot LEDs and Array LEDs two devices namely Billitron 2006 and Neotech sapphire 4000 demonstrated a drastic increase in maximum irradiance as the height was reduced from $30 \mathrm{~cm}$ to $15 \mathrm{~cm}$, from $91.9 \pm 1.6$ to $226 \pm 1.1$ and $101.2 \pm 1.2$ to $219.3 \pm 1.2$ respectively. Both these devices behaved more like spot LEDs in spite of the wider distribution of light sources across the panel. The other Multispot and Array LEDs demonstrated a more uniform increase as the height was decreased. Similar results were obtained for CFL devices. Two devices namely Billitron 2006(Multispot LED) and Neotech sapphire 4000(Array LED) had high maximum irradiance in the center but the mean irradiance across the measuring grid was low. This is explained by the uneven distribution of light footprint as shown in the surface plots for irradiance (Figure 1). The CFL units, Array LEDs (Brilliance classic, Brilliance Pro and Neotech Seefar) had a more uniform footprint.

The area of effective footprint showed a significant difference among the devices, Spot LEDs, Multispot LEDs and one of the Array LEDs (Neotech sapphire 4000) demonstrated a wider footprint at higher distance of $30 \mathrm{~cm}$ and decreased dramatically to less than $50 \%$ of the measuring grid (less than $900 \mathrm{~cm}^{2}$ ) at a height of $15 \mathrm{~cm}$, $25 \mathrm{~cm}$. Other devices (Brilliance classic, Brilliance Pro and Neotech Seefar 4000 and CFLs ) had an effective footprint of about 60 to $100 \%$ at different heights.

The decay of irradiance over time was maximum for CFL devices 0.31 and 0.29 respectively for Neotech CFL and Phoneix CFL. Among LEDs tested Spot LED namely Phoneix LED PT`100 had the maximum decay of irradiance. The data for the irradiance with tilt of 30 and 45 degrees show uneven distribution of irradiance for all the tested devices with a decrease in delivered irradiance with tilt angles. But one device (Brilliance Pro) performed consistently at different tilt angles. CFL devices showed an increase with increase in voltage changes but the LEDs did not show any significant change in irradiance with change in voltage. All the devices tested achieved a thermal equilibrium at around three hours. The temperature output of the CFL devices increased significantly from the baseline temperature by close to $7 \stackrel{\circ}{ } \mathrm{C}$. On the contrary the LEDs did not show such a significant increase in temperature except for Phoneix LED PT 100 and Array LEDs.

\section{Discussion}

The phototherapy systems tested did not emit light in the Ultraviolet or Infrared spectrum which is harmful for the neonate4. The tested units had a peak spectral wavelength centering close to the billirubin absorption spectrum. The LEDs had a very narrow band width compared to CFLs with wider band width. The surface plots of the irradiance footprint showed LEDs achieved a peak irradiance of more than $60 \mu \mathrm{W} / \mathrm{cm}^{2} / \mathrm{nm}$. The irradiance footprint however, differed significantly among the devices (Figure 1). Most of the LEDs tested had peak irradiances above the AAP recommendation [5] of $30 \mu \mathrm{W} / \mathrm{cm}^{2} / \mathrm{nm}$ or higher at all the distances measured. Among the LEDs, the Array LEDs had a uniform distribution of irradiance across the measuring grid. The Multispot LEDs gave bimodal or trimodal peaks of irradiance based on the distribution of the LEDs across the panel .The CFLs tested acheived the recommended $30 \mu \mathrm{W} / \mathrm{cm}^{2} / \mathrm{nm}$ or higher irradiances at distances lesser than $30 \mathrm{~cm}$. However the CFLs had uniform area of footprint at all heights tested which explain the similar clinical efficacy of CFLs in comparison with the LEDs demonstrated in previous literature [6].

Decreasing the height of overhead units increased the measured irradiance, but most of the LEDs tested had a substantial decrease in the footprint of the light as the devices were bought closer and the increase in the mean irradiance achieved was not significant (Tables 1-4). This was not the case with the CFL devices and the Array LEDs.

Table 1: Spectral Characteristics of the Light Sources.

\begin{tabular}{|c|c|c|c|c|c|c|c|}
\hline \multicolumn{2}{|c|}{ Phototherapy device systems } & \multirow{2}{*}{$\begin{array}{c}\begin{array}{r}\text { Peak emission } \\
\text { spectrum (nm) }\end{array} \\
450.7\end{array}$} & \multirow{2}{*}{$\begin{array}{c}\begin{array}{c}\text { Spectral } \\
\text { range(nm) }\end{array} \\
409-516\end{array}$} & \multirow{2}{*}{$\begin{array}{c}\begin{array}{c}\text { Band } \\
\text { width(nm) }\end{array} \\
25\end{array}$} & \multirow{2}{*}{$\begin{array}{c}\begin{array}{c}\text { Decay of irradiance* } \\
\text { microwatt } / \mathbf{c m}^{2} / \mathbf{n m} / \\
\text { day }\end{array} \\
0.04\end{array}$} & \multirow{2}{*}{$\begin{array}{c}\begin{array}{c}\text { Area of } \\
\text { footprint at } \\
\mathbf{3 0 \mathbf { c m }}\end{array} \\
650 \\
\end{array}$} & \multirow{2}{*}{$\begin{array}{c}\begin{array}{c}\text { Area of } \\
\text { footprint at } \\
15 \mathbf{c m}\end{array} \\
\mathrm{NA}^{*}\end{array}$} \\
\hline ס & Billitron 3006 & & & & & & \\
\hline spot LED & Phoenix PT 100 & 449 & $411-518$ & 26.5 & 0.16 & 1075 & 700 \\
\hline \multirow{2}{*}{$\begin{array}{c}\text { Multispot/ } \\
\text { Improvised LED }\end{array}$} & Billitron 2006 & 451.2 & $407-518$ & 23.9 & 0.04 & 775 & 775 \\
\hline & Billitron 5006 Sky & 447.5 & $405-506$ & 34 & 0.04 & 625 & 625 \\
\hline \multirow{3}{*}{ Array LED } & Brilliance & 453.5 & $408-520$ & 22 & 0.07 & 1425 & 1650 \\
\hline & Brilliance Pro & 450.7 & $414-511$ & 23.9 & 0.08 & 1125 & 975 \\
\hline & $\begin{array}{c}\text { Neotech Sappire } \\
4000\end{array}$ & 457 & $415-523$ & 32 & 0.08 & 825 & 650 \\
\hline
\end{tabular}




\begin{tabular}{|c|c|c|c|c|c|c|c|}
\hline \multirow{4}{*}{ CFL devices } & $\begin{array}{c}\text { Neotech Seefar } \\
4000\end{array}$ & 460.2 & $407-532$ & 32 & 0.09 & 1125 & 1100 \\
\cline { 2 - 7 } & \begin{tabular}{c} 
Neotech CFL PT \\
\cline { 2 - 7 }
\end{tabular} & $\begin{array}{c}\text { Phoenix CFL PT } \\
101\end{array}$ & 450.7 & $393-597$ & 65 & 0.31 & 1800 \\
180.7 & $395-594$ & 62 & 0.29 & 1800 & 1800 \\
\hline
\end{tabular}

Band width: "Absolute difference between the wavelengths at which the spectral radiant intensity is 50 percent of the maximum power output"

*IEC Standards: Optical spectrum of the light sources should not be in the harmful UV or IR spectrum

Table 2: Maximum and Mean Irradiance Measured at Different Height for the Different Phototherapy Systems Falling within the 2D Silhouette of Term Baby.

\begin{tabular}{|c|c|c|c|c|c|}
\hline \multicolumn{6}{|c|}{ Phototherapy Device Systems } \\
\hline & & \multicolumn{2}{|c|}{ At $30 \mathrm{~cm} \mathrm{\#}$} & \multicolumn{2}{|c|}{ At $15 \mathrm{~cm} \#$} \\
\hline & & Max & Mean & Max & Mean \\
\hline \multirow{2}{*}{ Spot LED } & Fanem Billitron 3006 & $58.9(1.1)$ & $14.5(0.7)$ & $N A^{*}$ & $N A^{*}$ \\
\hline & Phoenix PT 100 & $67.4(1.4)$ & $38.6(0.8)$ & $215.7(1.6)$ & $70.9(1.1)$ \\
\hline \multirow{2}{*}{ Multispot/Improvised LED } & Fanem Billitron 2006 & $91.9(1.6)$ & $30.5(0.7)$ & $226(1.1)$ & $61.4(1.0)$ \\
\hline & Fanem Billitron 5006 Sky & $54.4(0.9)$ & $9.2(0.5)$ & $117.9(1.1)$ & $14.4(0.5)$ \\
\hline \multirow{4}{*}{ Array LED } & Phoenix Brilliance & $28.5(0.5)$ & $16.9(0.3)$ & $52.2(0.5)$ & $28.0(0.4)$ \\
\hline & Phoenix Brilliance Pro & $46.8(0.8)$ & $26.4(0.5)$ & $89.4(0.9)$ & $37.4(0.6)$ \\
\hline & Neotech Sappire 4000 & 101.2(1.8) & $34.2(0.8)$ & $219.3(1.2)$ & $65.5(1.4)$ \\
\hline & Neotech Seefar 4000 & $83.7(1.6)$ & $50.5(1.1)$ & $95.5(1.5)$ & $59.9(1.3)$ \\
\hline \multirow{2}{*}{ CFL devices } & Neotech CFL PT & $26.2(0.5)$ & $18.8(0.2)$ & $68.8(0.5)$ & $39.2(0.4)$ \\
\hline & Phoenix CFL PT 101 & $32.2(0.5)$ & $21.7(0.3)$ & $66.3(0.5)$ & $36.7(0.4)$ \\
\hline
\end{tabular}

Height adjustments are not possible.

\#Height measurements: There may be a $\pm 0.5 \mathrm{~cm}$ difference in the actual measurements

Table 3: Variations In The Irradiance Distribution With Variations In Tilt And Heat Output Of The Devices At 25 Cm \#.

\begin{tabular}{|c|c|c|c|c|c|c|c|c|c|}
\hline \multicolumn{2}{|c|}{$\begin{array}{l}\text { Phototherapy device } \\
\text { sysytems }\end{array}$} & \multirow{2}{*}{$\begin{array}{c}\begin{array}{c}\text { Notilt Mean } \\
\text { Irradiance }\end{array} \\
\mathrm{NA}^{*}\end{array}$} & \multirow{2}{*}{ 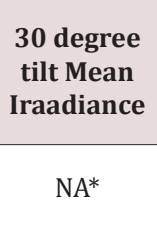 } & \multirow{2}{*}{$\begin{array}{c}\begin{array}{c}\text { Change } \\
\text { in mean } \\
\text { Irradiance } \\
\text { In\% }\end{array} \\
\mathrm{NA}^{*}\end{array}$} & \multirow{2}{*}{$\begin{array}{c}\begin{array}{c}45 \text { degree } \\
\text { tilt Mean } \\
\text { Irradiance }\end{array} \\
34.2\end{array}$} & \multirow{2}{*}{$\begin{array}{c}\begin{array}{c}\text { Change } \\
\text { in mean }\end{array} \\
\begin{array}{c}\text { Irradiance } \\
\text { in\% }\end{array} \\
40.8\end{array}$} & \multirow{2}{*}{$\begin{array}{c}\begin{array}{c}\text { Max Heat } \\
\text { output At } \\
\text { 1 Hour\# }\end{array} \\
40.3 \\
\end{array}$} & \multirow{2}{*}{$\begin{array}{c}\begin{array}{c}\text { Max Heat } \\
\text { output At } \\
\text { 3 Hour\# }\end{array} \\
\mathrm{NA}^{*}\end{array}$} & \multirow{2}{*}{$\begin{array}{c}\text { Max Heat } \\
\text { output At } 5 \\
\text { Hour\# }\end{array}$} \\
\hline Cnet IED & $\begin{array}{c}\text { Billitron } \\
3006\end{array}$ & & & & & & & & \\
\hline Spot LED & $\begin{array}{c}\text { Phoenix PT } \\
100\end{array}$ & $30.7(0.9)$ & $26.1(0.8)$ & -14.9 & 34.2 & 41.0 & 39.6 & $27.0(0.8)$ & -12.1 \\
\hline \multirow{2}{*}{$\begin{array}{l}\text { Multispot/ } \\
\text { Improvised } \\
\text { LED }\end{array}$} & $\begin{array}{c}\text { Billitron } \\
2006\end{array}$ & $22.1(0.5)$ & $22.7(0.5)$ & +2.6 & 34.2 & 39.6 & 40.3 & NA * & $\mathrm{NA}^{*}$ \\
\hline & $\begin{array}{l}\text { Billitron } \\
\text { 5006 Sky }\end{array}$ & $9.8(0.4)$ & $12.5(0.3)$ & +27.9 & 34.2 & 40.8 & 40.2 & $\mathrm{NA}^{*}$ & $\mathrm{NA}^{*}$ \\
\hline \multirow{4}{*}{ Array LED } & Brilliance & $19.6(0.3)$ & $16.4(0.3)$ & -16.5 & 34.2 & 39.7 & 39.0 & $13.3(0.3)$ & -32.2 \\
\hline & $\begin{array}{l}\text { Brilliance } \\
\text { Pro }\end{array}$ & $22.2(0.4)$ & $25.2(0.4)$ & +13.4 & 34.2 & 40.2 & 39.2 & $25.7(0.4)$ & +15.7 \\
\hline & $\begin{array}{c}\text { Neotech } \\
\text { Sappire } \\
4000\end{array}$ & $25.7(0.8)$ & $21.0(0.4)$ & -18.2 & 34.2 & 39.6 & 40.0 & $21.9(0.5)$ & -14.8 \\
\hline & $\begin{array}{c}\text { Neotech } \\
\text { Seefar } 4000\end{array}$ & $32.7(0.9)$ & $32.1(0.8)$ & -1.8 & 34.2 & 40.2 & 41.5 & $35.1(0.9)$ & +7.3 \\
\hline \multirow{2}{*}{ CFL devices } & $\begin{array}{c}\text { Neotech CFL } \\
\text { PT }\end{array}$ & $17.2(0.3)$ & $16.9(0.2)$ & -1.6 & 34.2 & 41.2 & 41.9 & $16.2(0.2)$ & -5.9 \\
\hline & $\begin{array}{l}\text { Phoenix CFL } \\
\text { PT } 101\end{array}$ & $19.3(0.3)$ & $18.7(0.2)$ & -3.2 & 34.2 & 42.6 & 42.3 & $18.2(0.2)$ & -5.7 \\
\hline
\end{tabular}


*Phototherapy unit is not tiltable

\#Measured at a room temperature of $34.2{ }^{\circ} \mathrm{C}$.

Table 4: Variations In Maximum Irradiance with Variations In Voltage At $35 \mathrm{Cm}$ \#.

\begin{tabular}{|c|c|c|c|c|c|c|c|c|}
\hline \multirow{2}{*}{\multicolumn{2}{|c|}{ Phototherapy Device System }} & \multicolumn{7}{|c|}{$\begin{array}{c}\text { Maximum Irradiance measurements } \\
\text { microwatt } / \mathrm{cm}^{2} / \mathrm{nm} \\
\text { Mean(S.D) }\end{array}$} \\
\hline & & At 240 Volts & At 180 Volts & $\%$ Change & At 210 Volts & $\%$ Change & At 270 Volts & $\%$ Change \\
\hline \multirow{2}{*}{ Spot LED } & Billitron 3006 & $61.5(0.2)$ & $61.5(0.2)$ & 0 & $61.5(0.2)$ & 0 & $61.6(0.2)$ & 0.16 \\
\hline & Phoenix PT 100 & $61.5(0.2)$ & $61.5(0.2)$ & 0 & $61.5(0.2)$ & 0 & $61.6(0.2)$ & 0.16 \\
\hline \multirow{2}{*}{$\begin{array}{l}\text { Multispot / } \\
\text { Improvised } \\
\text { LED }\end{array}$} & Billitron 2006 & $68.5(0.1)$ & $68.6(0.1)$ & 0.14 & $68.6(0.1)$ & 0.14 & $68.6(0.1)$ & 0.14 \\
\hline & Billitron 5006 Sky & $46.4(0.2)$ & $46.4(0.2)$ & 0 & $46.4(0.2)$ & 0 & $46.5(0.2)$ & 0.21 \\
\hline \multirow{4}{*}{ Array LED } & Brilliance & $44.3(0.2)$ & $44.3(0.2)$ & 0 & $44.3(0.2)$ & 0 & $44.3(0.2)$ & 0 \\
\hline & Brilliance Pro & $53.5(0.2)$ & $53.5(0.2)$ & 0 & $53.5(0.2)$ & 0 & $53.5(0.2)$ & 0 \\
\hline & Neotech Sappire 4000 & $64.3(0.2)$ & $64.5(0.1)$ & 0.31 & $64.5(0.1)$ & 0.31 & $64.5(0.2)$ & 0.31 \\
\hline & Neotech Seefar 4000 & $75.3(0.3)$ & $75.3(0.6)$ & 0 & $75.3(0.6)$ & 0 & $75.3(0.3)$ & 0 \\
\hline \multirow{2}{*}{ CFL devices } & Neotech CFL PT & $31.2(03)$ & $13.8(02)$ & -55.7 & $24.5(03)$ & -23.7 & $37.8(02)$ & 21.1 \\
\hline & Phoenix CFL PT 101 & $32.1(0.1)$ & $19.5(02)$ & -39.25 & $26.7(0.1)$ & -16.8 & $37.3(0.1)$ & 16.19 \\
\hline
\end{tabular}

\#Measurements made at $25 \mathrm{~cm}$. There may be a difference $\pm 0.5 \mathrm{~cm}$ in the height measurements.

This uneven distribution of the irradiance footprint led to a drop in the mean irradiance by more than 60 to $80 \mu \mathrm{W} / \mathrm{cm}^{2} / \mathrm{nm}$ in most of the spot and multispot LEDs. The foot print of most of the LEDs tested covered only around $75 \%$ of the two-dimensional body surface area of the hypothetical term 38 weeker baby which may be further decreased when the neonate moves across the bed mandating a light source -neonate relationship to be maintained while uses these Spot and Multispot LEDs. This difference in footprint would significantly reduce the overall efficacy of the phototherapy and must be considered during phototherapy application n clinical practice [7].

The decay of irradiance and the life span of a light source are influenced by factors like the duration of use, operating voltage, voltage fluctuations, manufacturing defects, frequency of cycling on and off and operating temperature, the ability of the unit to dissipate the heat generated. The tested devices showed decline in irradiance over time which was more with the CFLs compared to LEDs possibly due to exposure to voltage fluctuations and ineffective cooling of CFL bulbs in these devices.

The voltage fluctuations significantly affect the CFL devices performance while the LEDs are spared by the in build regulated power supply which converts the AC current to DC current before it reaches the LEDs .

Thermal equilibration point is influenced by several factors such as the environmental temperature, humidity, air currents and air exchanges that happen in the room. The temperature output of the phototherapy systems tested demonstrated a significant increase in heat output for CFL devices of up to $7^{\circ} \mathrm{C}$. This heat output is considered as inefficiency of the device to convert the electrical energy to light energy but may be of use in places where the ambient temperatures drop to less than $20^{\circ} \mathrm{C}$, especially in few places in north India were it would prevent neonates from becoming hypothermic while on phototherapy treatment.

\section{Conclusion}

Phototherapy units marketed in India are predominantly either CFL or LED based. LED phototherapy units are of different types like spot LEDs, Multi-spot or Improvised LEDs and Array LEDs. There are no existing Indian standards for optical spectral properties of phototherapy units. Most of the phototherapy units studied satisfy the minimum IEC standards but they differ a lot from each other in the three main determinants of efficacy of phototherapy treatment namely optical spectrum, irradiance and surface area covered (Light footprint). These differences may have a significant influence on the clinical benefits. CFL and Array LEDs had many of characteristics that fulfill the AAP recommendations for an ideal device .These spectral properties must be considered into while choosing a device for treating neonatal jaundice.

\section{Acknowledgment}

Prof Subramony and Mr.Uday kumar Ph.D student of the Department of Physics, Indian Institute of Technology, Chennai for their help in providing the optical spectrum analyzer and light intensity meter.

\section{References}

1. Vreman HJ, Wong RJ, Stevenson DK (2004) Phototherapy: Current methods and future direction Semin Perinatol 28(5): 326-333. 
2. (2000) International Electrotechnical Commission. Medical Electrical Equipment - Part 2-50: Particular Requirements for the Safety of Infant Phototherapy Equipment. IEC 60601-2-50.

3. Vreman HJ, Wong RJ, Murdock JR, Stevenson DK (2008) Standardized bench method for evaluating the efficacy of phototherapy devices. Acta Pediatrica 97 (3): 308-316.

4. Subramanian S, Sankar MJ, Deorari AK, Velpandian T, Kannan P, et al. (2011) Evaluation of phototherapy devices used for neonatal hyperbillirubinemia. Indian Pediatr 48(9): 689-96.
5. Bhutani VK (2011) Committee on Fetus and Newborn; American Academy of Pediatrics. Phototherapy to prevent severe neonatal hyperbillirubinemia in the newborn infant 35 or more weeks of gestation. Pediatrics 128(4):1046-1052

6. Kumar P, Chawla D, Deorari A (2011) Light emitting diode phototherapy for unconjugated hyperbillirubinemia in neonates .Cochrane Database of Systematic Review 7(12).

7. Hart G, Cameron R (2005) the importance of irradiance and area in neonatal phototherapy. Arch Dis Child Fetal Neonatal Ed 90(5): F437440 .

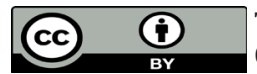

This work is licensed under Creative Commons Attribution 4.0 License

To Submit Your Article Click Here:

Submit Article

DOI: $10.32474 /$ PAPN.2018.01.000117

$\begin{gathered}\text { Progressing Aspects in Pediatrics } \\ \text { and Neonatology }\end{gathered}$
Assets of Publishing with us
- Global archiving of articles
- Immediate, unrestricted online access
- Rigorous Peer Review Process
- Authors Retain Copyrights
- Unique DOI for all articles

